\title{
Nodulação e produção de feijão-caupi em resposta à inoculação com diferentes densidades rizobianas
}

\author{
Elson Barbosa da Silva Júnior ${ }^{(1)}$, Krisle da Silva( ${ }^{(2)}$, Suzinei Silva Oliveira(3), Paulo Jansen de Oliveira(4), \\ Robert Michael Boddey(5), Jerri Édson Zilli ${ }^{(5)}$ e Gustavo Ribeiro Xavier ${ }^{(5)}$
}

\begin{abstract}
(1)Universidade Federal Rural do Rio de Janeiro (UFRRJ), Instituto de Agronomia, Departamento de Solos, BR 465, Km 7, CEP 23890-000 Seropédica, RJ, Brasil. E-mail: elsonlica@yahoo.com.br (2)Embrapa Roraima, Rodovia BR-174, Km 8, Distrito Industrial, CEP $69301-970$ Boa Vista, RR, Brasil. E-mail: krisle.silva@embrapa.br ${ }^{(3)}$ Embrapa Agrossilvipastoril, Rodovia MT 222, Km 2,5, CEP $78550-970$ Sinop, MT, Brasil. E-mail: suzinei.oliveira@embrapa.br (4)UFRRJ, Instituto de Tecnologia, Departamento de Engenharia Química. E-mail: pjansen@ufrrj.br (5)Embrapa Agrobiologia, Rodovia BR 465, Km 7, CEP 23890-000 Seropédica, RJ, Brasil. E-mail: robert.boddey@embrapa.br, jerri.zilli@embrapa.br, gustavo.xavier@embrapa.br
\end{abstract}

Resumo - O objetivo deste trabalho foi avaliar a resposta da cultura do feijão-caupi a diferentes densidades de células rizobianas aplicadas na semente, em condições de campo. Foram realizados quatro experimentos no Brasil: dois na região Norte, em área já cultivada e em área de primeiro cultivo; um na região Centro-Oeste; e um na região Sudeste. Utilizou-se o delineamento experimental de blocos ao acaso, com quatro repetições. Os tratamentos consistiram das seguintes densidades de células da estirpe BR 3267 ou da estirpe BR 3262: 0,

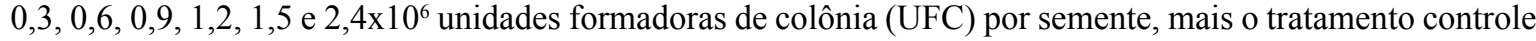
sem inoculação e com adição de fertilizante nitrogenado $\left(70 \mathrm{~kg} \mathrm{ha}^{-1} \mathrm{de} N\right)$. Foram analisadas as variáveis massa de matéria seca dos nódulos e da parte aérea, e rendimento de grãos secos (13\% de umidade). Para avaliar a nodulação, foram coletadas cinco plantas sequencialmente aos 30-35 dias após a emergência, na segunda linha de cada parcela. A nodulação respondeu positivamente ao aumento da densidade de células de rizóbios aplicada nas sementes. Houve aumento linear da nodulação das plantas com o aumento da densidade da inoculação; porém, não necessariamente com resposta na biomassa da parte aérea. O maior rendimento de grãos ocorre na densidade de pelo menos $1,2 \times 10^{6}$ unidades formadoras de colônia por semente.

Termos para indexação: Bradyrhizobium, Vigna unguiculata, fixação biológica, inoculante, produtividade.

\section{Cowpea nodulation and production in response to inoculation with different rhizobia densities}

\begin{abstract}
The objective of this work was to evaluate the cowpea crop response to different densities of rhizobia cells applied to the seed under field conditions. Four experiments were carried out in Brazil: two in the North Region, in an already-cultivated area and in a first-crop area; one in the Central-West Region; and one in the Southeast Region. The experimental design was a randomized complete block with four replicates. The treatments consisted of the following cell densities of the BR 3267 strain or of the BR 3262 strain: 0, $0.3,0.6,0.9,1.2,1.5$, and $2.4 \times 10^{6}$ colony-forming units (CFU) per seed, plus the control treatment without inoculation and with the addition of nitrogen fertilization $\left(70 \mathrm{~kg} \mathrm{ha}^{-1} \mathrm{~N}\right)$. The evaluated variables were nodule dry weight, shoot dry weight, and dry grain yield (13\% moisture). To assess nodulation, five plants were collected sequentially at 30-35 days after emergence in the second row of each plot. Nodulation responded positively to the increase in rhizobia cell density applied to the seeds. There was a linear increase in plant nodulation with the increase of inoculation density; however, not necessarily with a response in shoot biomass. The highest grain yield occurs at a density of at least $1.2 \times 10^{6}$ colony-forming units per seed.
\end{abstract}

Index terms: Bradyrhizobium, Vigna unguiculata, biological fixation, inoculant, productivity.

\section{Introdução}

A cultura do feijão-caupi [Vigna unguiculata (L.) Walp.] nas regiões Norte e Nordeste do Brasil tem sido caracterizada como de baixo aporte tecnológico, com resultados em produtividade de grãos inferiores a
$400 \mathrm{~kg} \mathrm{ha}^{-1}$ (Freire Filho, 2011). Contudo, nos últimos anos, tem-se observado grande expansão da cultura também para o Cerrado da região Centro-Oeste, especialmente para o Estado do Mato Grosso. Nessas áreas, o feijão-caupi é cultivado na safrinha, com rendimento de grãos ao redor de $1.000 \mathrm{~kg} \mathrm{ha}^{-1}$ (Filgueiras

Pesq. agropec. bras., Brasília, v.49, n.10, p.804-812, out. 2014

DOI: 10.1590/S0100-204X2014001000007 
et al., 2009); esse novo processo de desenvolvimento da cultura pode ser atribuído, em grande parte, ao seu potencial no agronegócio.

O feijão-caupi vem sendo intensamente pesquisado, com destaque para estudos voltados para o melhoramento genético, o manejo da cultura e a fixação biológica de nitrogênio (FBN). Para a FBN, diversos trabalhos de seleção de estirpes (Martins et al., 2003; Soares et al., 2006; Zilli et al., 2009) e de novos veículos para formulação de inoculantes (Fernandes Júnior et al., 2009, 2012; Silva Júnior et al., 2012) foram realizados, e os resultados obtidos auxiliaram na ampliação da área inoculada com feijão-caupi, tendose comercializado mais de 150 mil doses de inoculantes para a cultura, em 2012 (Associação Nacional dos Produtores e Importadores de Inoculante - ANPII).

Atualmente, quatro estirpes - UFLA 3-84 (SEMIA 6461), INPA 03-11B (SEMIA 6463), BR 3267 (SEMIA 6462) e BR 3262 (SEMIA 6464) - são autorizadas para uso em inoculantes para a cultura do feijão-caupi (Brasil, 2011); algumas marcas comerciais estão disponíveis, no mercado, em veículo turfoso ou líquido.

Os primeiros resultados significativos da inoculação do feijão-caupi foram observados por Martins et al. (2003), com a inoculação da cultivar IPA 206 com a estirpe BR 3267, que proporcionou produtividade de $693 \mathrm{~kg} \mathrm{ha}^{-1}$, similar à do tratamento controle com fertilizante nitrogenado. No caso das estirpes INPA 03-11B e UFLA 3-84, quando testadas nas cultivares BR 14-Mulato e BR 08-Caldeirão, o rendimento de grãos foi de 950 e $1.340 \mathrm{~kg} \mathrm{ha}^{-1}$, respectivamente, em resposta à adubação nitrogenada de 70 e $80 \mathrm{~kg} \mathrm{ha}^{-1}$ de $\mathrm{N}$, na forma de ureia (Lacerda et al., 2004). A última estirpe recomendada, BR 3262, foi testada na safra agrícola de Roraima, inoculada em sementes de feijão-caupi da cultivar BRS Mazagão, o que proporcionou rendimentos de grãos superiores a $2.000 \mathrm{~kg} \mathrm{ha}^{-1}$, cerca de $30 \%$ maiores que o do controle absoluto (Zilli et al., 2009).

No entanto, nem sempre os resultados da inoculação em campo são positivos, como constatado nos trabalhos de: Borges et al. (2012), em que a testemunha (sem inoculação) proporcionou rendimento de grãos superior ao da inoculação com as estirpes recomendadas; e de Chagas Junior et al. (2010) e Costa et al. (2011), em que a testemunha também proporcionou rendimento de grãos similar ao das estirpes recomendadas. Isso provavelmente se deve à baixa fertilidade dos solos, à variabilidade entre cultivares (Marinho et al., 2014), à baixa especificidade das bactérias nativas do solo para nodulação do feijão-caupi (Martins et al., 2003; Silva et al., 2012) ou ao fato de ainda não se ter estabelecido a densidade de células rizobianas ideal a ser aplicada na semente. Nesse sentido, há a necessidade de elevar a competitividade das estirpes do inoculante. Segundo Silva et al. (2012), a densidade rizobiana ideal para a inoculação tende a contribuir para o aumento de produtividade. Krasova-Wade et al. (2006) observaram que o uso de uma densidade rizobiana elevada na inoculação é uma forma de aumentar a competitividade das estirpes inoculadas contra a população rizobiana nativa.

De acordo com Thies et al. (1991), a presença de uma população nativa de rizóbios do solo adequada para atender aos requisitos de fixação do $\mathrm{N}_{2}$ da planta foi a principal razão de as culturas não responderem à inoculação. Já Soares et al. (2014) verificaram que a população nativa em estudo proporcionou massa da parte aérea similar à do controle com fertilizante nitrogenado. Porém, nem sempre a população nativa é eficiente. Pule-Meulenberg et al. (2010), em estudo em Ghana, constataram que genótipos de feijão-caupi não inoculado proporcionaram $100 \mathrm{mg}$ de nódulos secos, que possibilitaram diferentes rendimentos de grãos: um genótipo com $252 \mathrm{~kg} \mathrm{ha}^{-1}$ e outro com $686 \mathrm{~kg} \mathrm{ha}^{-1}$. Belane \& Dakora (2010), ao avaliar plantas de feijão-caupi não inoculadas aos 67 dias após o plantio, encontraram variação de 56,2 a $96,3 \%$ do $\mathrm{N}$ oriundo da FBN em função da cultivar. Isso evidencia que a população nativa de rizóbios do solo apresenta eficiência variável, o que justifica a necessidade da inoculação com densidade ideal. Silva et al. (2012) relataram aumento da nodulação das plantas, em condições de casa de vegetação, com a elevação da taxa de inóculo. Entretanto, para feijão-caupi, ainda não foi estabelecida uma dose ideal de inoculante para as sementes em condições de campo.

O objetivo deste trabalho foi avaliar a resposta da cultura do feijão-caupi a diferentes densidades de células rizobianas aplicadas nas sementes, em condições de campo.

\section{Material e Métodos}

Foram realizados quatro experimentos em campo, em condições distintas, em 2011: dois experimentos

Pesq. agropec. bras., Brasília, v.49, n.10, p.804-812, out. 2014 DOI: 10.1590/S0100-204X2014001000007 
na região Norte, em Boa Vista, RR; um na região Centro-Oeste, em Sinop, MT; e outro na região Sudeste, em Seropédica, RJ. Os dois experimentos na região Norte foram instalados no campo experimental Água Boa, da Embrapa Roraima ( $\left.02^{\circ} 15^{\prime} 00^{\prime \prime} \mathrm{N}, 60^{\circ} 39^{\prime} 54^{\prime \prime W}\right)$, em Latossolo Amarelo distrófico (Santos et al., 2006), com precipitação no período de 375,3, 308,5 e 200 $\mathrm{mm}$ em julho, agosto e setembro, respectivamente. A diferença entre as duas áreas experimentais é que uma havia sido cultivada com soja [Glycine max (L.) Merr.], nas duas safras anteriores e, portanto, apresentava população de rizóbios estabelecida, enquanto a outra era área recém-aberta para o cultivo, sem histórico de inoculação. Na região Centro-Oeste, o experimento foi conduzido na área experimental da Embrapa Agrossilvipastoril $\left(11^{\circ} 51^{\prime} 29^{\prime \prime} \mathrm{S}, \quad 55^{\circ} 36^{\prime} 2^{\prime \prime} \mathrm{W}\right)$, em Latossolo Vermelho-Amarelo distrófico (Santos et al., 2006), com precipitação no período de 150, 390 e 140 $\mathrm{mm}$ em dezembro, janeiro e fevereiro, respectivamente. A área apresentava histórico de dez anos de cultivo de soja, com população de rizóbios estabelecida. $\mathrm{O}$ experimento na região Sudeste foi conduzido na área experimental da Embrapa Agrobiologia $\left(22^{\circ} 45^{\prime} \mathrm{S}\right.$, $43^{\circ} 40^{\prime} \mathrm{W}$ ), em Argissolo Amarelo distrófico (Santos et al., 2006), em área sob pousio, que, nos três anos anteriores, havia sido cultivada com cana-de-açúcar (Saccharum officinarum L.) por dois anos consecutivos. A precipitação no período foi de 110, 90 e $120 \mathrm{~mm}$ em outubro, novembro e dezembro, respectivamente.

Em todos os experimentos, foi utilizada a cultivar de feijão-caupi BRS Guariba, recomendada para uso em âmbito nacional (Freire Filho, 2011). Quanto à inoculação, na região Norte, foi utilizada a estirpe de Bradyrhizobium sp. BR 3262 (SEMIA 6464) em veículo turfoso, recomendada para a região (Zilli et al., 2009); e, nas regiões Sudeste e Centro-Oeste, foi utilizada a estirpe de Bradyrhizobium sp. BR 3267 (SEMIA 6462) em veículo polimérico IPC 2.2 (Fernandes Júnior et al.,
2012; Silva Júnior et al., 2012), que já proporcionou resultados favoráveis na região Sudeste (Silva Júnior et al., 2012) e está em teste na região Centro-Oeste.

No experimento na região Sudeste, os tratamentos consistiram na inoculação de sementes contendo as concentrações de: $0,0,3,0,6,1,2,1,5$ e $2,4 \times 10^{6}$ unidades formadoras de colônia (UFC) por semente. Nos dois experimentos na região Norte, as sementes foram inoculadas com $0,0,3,0,6,1,2$ e $2,4 \times 10^{6} \mathrm{UFC}$ por semente. Na região Centro-Oeste, os tratamentos foram otimizados, com a inoculação das sementes com $0,0,9,1,2$ e $1,5 \times 10^{6}$ UFC por semente. Em todos os experimentos, foi acrescido um tratamento controle com adubação nitrogenada, na dose de $70 \mathrm{~kg} \mathrm{ha}^{-1}$ de N na forma de ureia $(45 \%$ de $\mathrm{N})$, conforme o recomendado para experimentos em campo (Brasil, 2011), com aplicação na semeadura e no início da floração (aproximadamente 25-30 dias após a emergência das plantas), na proporção de $1 / 4$ do total de $\mathrm{N}$ na primeira aplicação e o restante na segunda.

A padronização da densidade de UFC por semente na inoculação foi baseada em inoculantes contendo uma ordem de grandeza de $10^{9}$ UFC por grama de inoculante e 5.000 sementes de feijão-caupi por $\mathrm{kg}$, de acordo com recomendação do Ministério da Agricultura, Pecuária e Abastecimento (Brasil, 2011). Assim, tem-se: densidade (UFC por semente) = (quantidade de inoculante $\mathrm{g}$ ou $\mathrm{mL} \times$ concentração do inoculante UFC) / número de sementes.

A análise de fertilidade do solo antes da semeadura foi realizada na profundidade de 0 a $20 \mathrm{~cm}$ (Tabela 1), para os quatro experimentos, conforme Embrapa (Claessen et al., 1997); também foi realizada análise granulométrica.

Utilizou-se o delineamento experimental de blocos ao acaso, com quatro repetições. Os tratamentos foram compostos pelas seguintes densidades de células da estirpe BR 3267 ou da estirpe BR 3262: 0, 0,3, 0,6,

Tabela 1. Análise química e granulométrica do solo da camada de 0 a $20 \mathrm{~cm}$ de profundidade dos experimentos conduzidos nas regiões Norte, Centro-Oeste e Sudeste do Brasil.

\begin{tabular}{|c|c|c|c|c|c|c|c|c|c|c|}
\hline \multirow[t]{2}{*}{ Área experimental } & \multirow{2}{*}{$\begin{array}{c}\mathrm{pH} \mathrm{em} \\
\mathrm{H}_{2} \mathrm{O}\end{array}$} & $\mathrm{Al}$ & $\mathrm{Ca}$ & $\mathrm{Mg}$ & \multirow{2}{*}{$\begin{array}{c}\mathrm{MO}^{(1)} \\
\left(\mathrm{g} \mathrm{dm}^{-3}\right)\end{array}$} & \multirow{2}{*}{\multicolumn{2}{|c|}{$\begin{array}{c}\mathrm{P} \\
\mathrm{-}\end{array}$}} & \multicolumn{3}{|c|}{ Análise granulométrica $\left(\mathrm{g} \mathrm{kg}^{-1}\right)$} \\
\hline & & ------ & $\mathrm{ol}_{\mathrm{c}} \mathrm{dr}$ & -1-- & & & & Areia & Silte & Argila \\
\hline Região Norte, 1ํo cultivo $^{(2)}$ & 5,4 & 0,0 & 0,9 & 0,30 & 10,8 & 26,2 & 11,7 & 840 & 10 & 150 \\
\hline Região Norte, cultivada ${ }^{(3)}$ & 5,6 & 0,0 & 1,4 & 0,29 & 11,7 & 38,1 & 31,2 & 840 & 10 & 150 \\
\hline Região Centro-Oeste & 5,2 & 0,17 & 1,88 & 0,40 & 34,9 & 6,71 & 72 & 750 & 10 & 240 \\
\hline Região Sudeste & 5,2 & 0,08 & 0,88 & 0,17 & 6,5 & 18,93 & 32 & 880 & 10 & 110 \\
\hline
\end{tabular}

${ }^{(1)} \mathrm{MO}$, matéria orgânica. ${ }^{(2)}$ Área de primeiro cultivo. ${ }^{(3)}$ Área com cultivo anterior de soja (Glycine max). 
$0,9,1,2,1,5$ e $2,4 \times 10^{6}$ UFC por semente, mais o tratamento controle sem inoculação e com adição de fertilizante nitrogenado $\left(70 \mathrm{~kg} \mathrm{ha}^{-1} \mathrm{de} \mathrm{N}\right)$. Cada parcela com tamanho de $24 \mathrm{~m}^{2}$ (4x6 m) conteve oito linhas de semeadura, com distância de 1,5 m entre parcelas.

As variáveis analisadas foram: massa de matéria seca dos nódulos e da parte aérea, e rendimento de grãos secos (13\% de umidade). A nodulação dos experimentos foi avaliada a partir da coleta de cinco plantas sequencialmente aos 30-35 dias após a emergência, na segunda linha de cada parcela. A massa de matéria seca dos nódulos e da parte aérea foram mensuradas após secagem em estufa de circulação forçada, com temperatura ajustada a $65^{\circ} \mathrm{C}$, até massa constante.

Os dados foram submetidos à análise de variância pelo teste $\mathrm{F}$, a $10 \%$ de probabilidade, com auxílio do programa Sisvar v.4.5 (Ferreira, 2008). Foram ajustadas equações de regressão linear, quadrática e cúbica significativas para as variáveis massa de matéria seca de nódulos e de parte aérea; e o rendimento de grãos secos foi avaliado em função do aumento da densidade de células rizobianas inoculadas nas sementes. Para a variável rendimento de grãos secos, foi utilizado o teste $\mathrm{t}$ (LSD), a $5 \%$ de probabilidade, após análise de variância, para comparar a produtividade das plantas inoculadas à daquelas que receberam adubação nitrogenada.

\section{Resultados e Discussão}

A massa seca de nódulos em função do aumento da densidade de células de rizóbios aplicadas nas sementes apresentou equações de regressão significativas (Figura 1), o que corrobora os resultados de Silva et al. (2012), exceto para a área de primeiro cultivo na região Norte, que não se ajustou à nenhuma regressão; nesse mesmo experimento, a melhor resposta à inoculação para essa variável foi obtida na densidade de $1,2 \times 10^{6}$ UFC por semente. A área que já havia recebido cultivos anteriores na região Norte e o experimento no Centro-Oeste responderam de forma linear ao aumento da densidade na inoculação, enquanto o experimento no Sudeste respondeu de forma cúbica, mas com valor de $\mathrm{R}^{2}$ baixo.

$\mathrm{O}$ experimento conduzido na região Sudeste mostrou alta nodulação no tratamento sem inoculante, com massa de nódulos acima de $200 \mathrm{mg}$ por planta
(Figura 1), o que indica a presença de rizóbios já estabelecidos no solo. Mesmo nessa condição, observou-se aumento numérico da nodulação com a inoculação de até $0,6 \times 10^{6}$ UFC por semente, tendose chegado a um valor próximo a $300 \mathrm{mg}$ por planta. Após esta densidade, no entanto, houve uma aparente redução da nodulação das plantas e um novo aumento na densidade de $2,4 \times 10^{6}$ UFC por semente; porém, todos os valores permaneceram próximos de $200 \mathrm{mg}$ por planta, o que evidenciou que, mesmo com a presença de bactérias no solo, a inoculação elevou a nodulação.

No experimento na região Norte, em área cultivada anteriormente com soja, houve correlação positiva entre a densidade de rizóbios e o aumento da nodulação, com comportamento linear para a nodulação até a densidade de $2,4 \times 10^{6}$ UFC por semente (Figura 1). Já na área recém cultivada, todos os tratamentos apresentaram alta nodulação. Essa alta nodulação, provavelmente, é consequência da população nativa, como já observado em área nativa na região Norte, com população de

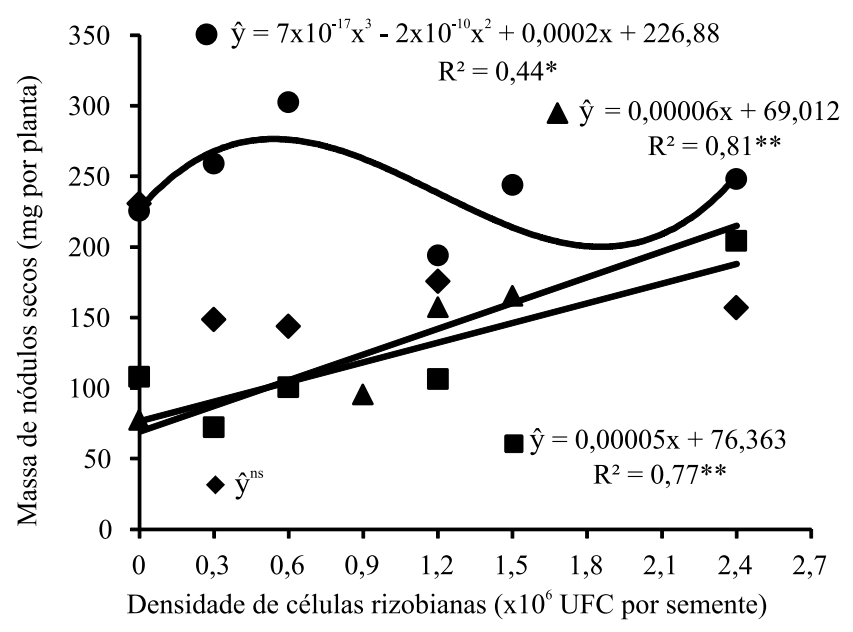

- Norte ( $1^{\circ}$ cultivo) $\mathbf{D}$ Norte (cultivada) $\Delta$ Centro-Oeste

Figura 1. Massa seca de nódulos por planta de feijão-caupi (Vigna unguiculata) 'BRS Guariba', 35 dias após emergência, em resposta a diferentes densidades de células rizobianas aplicadas por semente e em diferentes localidades no Brasil. $\mathrm{Na}$ região Norte, em área de primeiro cultivo e em área já cultivada, ambas em Boa Vista, RR; na região Centro-Oeste, em Sinop, MT; e, na região Sudeste, em Seropédica, RJ. ** e *significativo a 5 e $10 \%$ de probabilidade, respectivamente. ns Não significativo. Coeficientes de variação: na região Norte, em área já cultivada, de 21,49\%; na região Centro-Oeste, de $17,86 \%$; e, na região Sudeste, de 24,66\%. 
rizóbios estabelecida capaz de nodular o feijão-caupi (Zilli et al., 2013). Isso evidencia, assim como o observado no experimento na região Sudeste, que, possivelmente, a alta população de rizóbios do solo foi capaz de ocupar os sítios de nodulação disponíveis e que o aumento da densidade não promoveu aumento da nodulação. Na região Norte, Zilli et al. (2009) também obtiveram resultados similares para massa de nódulos, ao avaliar um inoculante com a estirpe BR 3262 na densidade de $0,6 \times 10^{6}$ UFC por semente, em área de Cerrado, na safra 2006, e de mata alterada, na safra 2005/2006. Esses autores observaram que a massa de nódulos foi superior a $150 \mathrm{mg}$ por planta, resultado semelhante aos obtidos em ambos os experimentos na mesma região, no presente trabalho, em que a massa de nódulos foi superior a $100 \mathrm{mg}$ por planta no tratamento sem inoculação.

A massa de nódulos do experimento no Centro-Oeste aumentou de forma linear em função da densidade da inoculação (Figura 1), tendo-se obtido a maior massa de nódulos entre tratamentos com a inoculação de $1,5 \times 10^{6}$ UFC por semente. Esses dados estão de acordo com os encontrados por Silva et al. (2012), que avaliaram a taxa de inóculo com a estirpe BR 3267, em casa de vegetação, e observaram incremento na nodulação, na FBN e no crescimento de plantas de feijão-caupi com o aumento da densidade rizobiana na inoculação.

A densidade ideal na inoculação é uma ferramenta que pode reduzir a influência da população nativa de rizóbios do solo no momento da nodulação (Figura 1). $\mathrm{Na}$ região Centro-Oeste, foi observada população de Bradyrhizobium no solo estabelecida em função de cultivos com soja, em anos anteriores (Mendes et al., 2004). Em casa de vegetação, Zilli et al. (2011) constataram que as estirpes recomendadas para soja também podem nodular o feijão-caupi, mas com eficiência variável, o que reduz os benefícios da FBN.

Não foram obtidas equações de regressão significativas quanto à massa da parte aérea em resposta ao aumento da densidade de rizóbios na inoculação de sementes (Figura 2). Costa et al. (2011) e Borges et al. (2012) relataram massa da parte aérea similar e até superior nas plantas não inoculadas, quando comparado à inoculação com as estirpes recomendadas. Porém, o aumento da massa da parte aérea não significa diretamente aumento da produtividade. Ferreira et al. (2013) verificaram que a inoculação com a estirpe BR 3262 proporcionou massa da parte aérea similar à da testemunha (sem inoculação); contudo, ao avaliar o rendimento de grãos, observaram que a estirpe produziu o dobro da testemunha.

Nas regiões Sudeste e Norte (área anteriormente cultivada com soja), o rendimento de grãos respondeu de forma significativa ao aumento da densidade de rizóbios na inoculação (Figura 3). As equações quadráticas obtidas indicaram que o maior rendimento de grãos ocorreu quando a cultura foi inoculada com a densidade de rizóbios de $1,2 \times 10^{6}$ UFC por semente. Já no experimento na região Centro-Oeste, o rendimento de grãos respondeu de forma linear ao aumento da densidade de rizóbios na inoculação.

A análise de regressão mostrou que, na região Sudeste e em ambas as áreas na região Norte, o rendimento de grãos com a inoculação na densidade de bactérias de $1,2 \times 10^{6}$ UFC por semente ficou acima do proporcionado pela densidade de $2,4 \times 10^{6}$ UFC por semente. No entanto, ao se considerar a análise de variância dos dados de forma independente, observouse que as doses de 1,2 e $2,4 \times 10^{6}$ UFC por semente foram significativamente iguais (Tabela 2). Esses



- Norte $\left(1^{\circ}\right.$ cultivo) $\mathbf{a}$ Norte (cultivada) $\Delta$ Centro-Oeste

Figura 2. Massa seca da parte aérea por planta de feijão-caupi (Vigna unguiculata) 'BRS Guariba', 35 dias após emergência, em função de diferentes densidades de células rizobianas aplicadas por semente e em diferentes localidades no Brasil. $\mathrm{Na}$ região Norte, em área de primeiro cultivo e em área já cultivada, ambas em Boa Vista, RR; na região Centro-Oeste, em Sinop, MT; e, na região Sudeste, em Seropédica, RJ. Dados não significativos na curva de regressão (ns). 
dados mostram que pode haver densidade máxima de células de rizóbios nas sementes, o que aumenta a nodulação e, consequentemente, a produção das plantas, diferentemente do observado para a cultura da soja até o momento (Campo et al., 2010; Silva et al., 2011).

A inoculação das sementes com uma densidade de células de rizóbios que não seja a ideal pode ser um dos motivos da falta de resposta do rendimento de grãos à inoculação com as estirpes recomendadas. Chagas Junior et al. (2010) relataram que, para a cultivar de feijão-caupi BRS Novaera, o tratamento sem inoculação proporcionou rendimento de grãos superior ao da inoculação com a estirpe BR 3262 e similar ao obtido com a INPA 03-11B e a BR 3267. Costa et al. (2011) também verificaram que, para a cultivar BR 17 Gurguéia, o tratamento sem inoculação proporcionou rendimento de grãos similar para as estirpes BR 3267 e UFLA 3-84. Por sua vez, Borges et al. (2012), ao avaliar

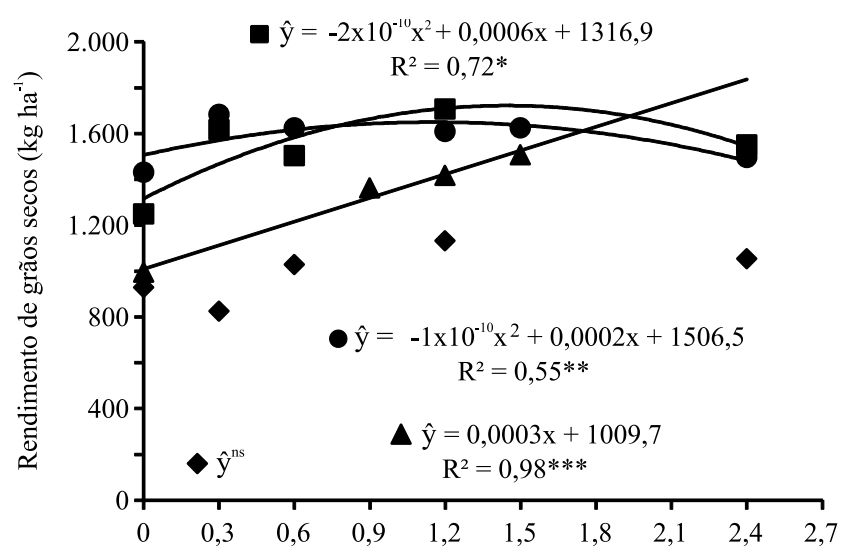

Densidade de células rizobianas (x $10^{6}$ UFC por semente)

- Norte $\left(1^{\circ}\right.$ cultivo) $\quad \boldsymbol{D}$ Norte (cultivada) $\Delta$ Centro-Oeste $\quad$ Sudeste

Figura 3. Rendimento de grãos secos de feijão-caupi (Vigna unguiculata) 'BRS Guariba', 75 dias após emergência, em função de diferentes densidades de células rizobianas aplicadas por semente e em diferentes localidades no Brasil. Na região Norte, em área de primeiro cultivo e em área já cultivada, ambas em Boa Vista, RR; na região Centro-Oeste, em Sinop, MT; e, na região Sudeste, em Seropédica, RJ. $* * *, * *$ e $*$ Significativo a 1,5 e $10 \%$ de probabilidade, respectivamente. ${ }^{\text {ns }}$ Não significativo. Coeficientes de variação: na região Norte, em área já cultivada, de 18,77\%; na região Centro-Oeste, de 10,86\%; e, na região Sudeste, de $9,06 \%$. a cultivar Vinagre, observaram que o tratamento sem inoculação proporcionou rendimento de grãos superior ao da inoculação com todas as estirpes atualmente recomendadas.

O aumento da densidade de rizóbios na inoculação aumentou a produtividade no experimento no Centro-Oeste; o maior valor, de $1.506 \mathrm{~kg} \mathrm{ha}^{-1}$, foi alcançado com a densidade de $1,5 \times 10^{6}$ UFC por semente. Verificou-se que o tratamento inoculado com $1,5 \times 10^{6}$ UFC por semente proporcionou aumento de $144 \mathrm{~kg} \mathrm{ha}^{-1}$, quando comparado à densidade de $0,9 \times 10^{6}$ UFC por semente; entretanto, em comparação à densidade de $1,2 \times 10^{6}$ UFC por semente, o aumento correspondeu a apenas $35 \mathrm{~kg} \mathrm{ha}^{-1}$. Esse aumento da produtividade em função do aumento da densidade de células aplicadas nas sementes corrobora dados de Campo et al. (2010), que, ao avaliar o aumento da dose de inoculação com inoculante líquido para soja, constataram que o aumento da densidade de rizóbios na inoculação de sementes proporcionou maior rendimento de grãos.

Em geral, todos os tratamentos inoculados, independentemente da densidade de bactérias nas sementes, proporcionaram rendimento de grãos igual ao do tratamento que recebeu adubação nitrogenada, em três dos quatro experimentos (Tabela 2). Apenas na área de primeiro cultivo na região Norte, o tratamento

Tabela 2. Rendimento de grãos secos em função da densidade de rizóbios na inoculação de sementes de feijão-caupi (Vigna unguiculata), em resposta à adubação com $70 \mathrm{~kg} \mathrm{ha}^{-1}$ de $\mathrm{N}$, em experimentos nas regiões Norte, Centro-Oeste e Sudeste do Brasil $^{(1)}$.

\begin{tabular}{lcccc}
\hline \multirow{2}{*}{$\begin{array}{l}\text { Densidade } \\
\left(\times 10^{6} \text { UFC por semente) }\right.\end{array}$} & \multicolumn{4}{c}{ Rendimento de grãos $\left(\mathrm{kg} \mathrm{ha}^{-1}\right)$} \\
\cline { 2 - 5 } & Sudeste & $\begin{array}{c}\text { Norte }- \\
10\end{array}$ & $\begin{array}{c}\text { Norte }- \\
\text { cultivo }^{(2)} \\
\text { cultivada }^{(3)}\end{array}$ & $\begin{array}{c}\text { Centro } \\
- \text {-Oeste }\end{array}$ \\
\hline 0 & $1.430 \mathrm{~b}$ & $929 \mathrm{cb}$ & $1.250 \mathrm{~b}$ & $994 \mathrm{~b}$ \\
0,3 & $1.683 \mathrm{a}$ & $824 \mathrm{c}$ & $1.615 \mathrm{ba}$ & $-(4)$ \\
0,6 & $1.623 \mathrm{ba}$ & $1.027 \mathrm{cba}$ & $1.504 \mathrm{ba}$ & - \\
0,9 & - & - & - & $1.362 \mathrm{a}$ \\
1,2 & $1.608 \mathrm{ba}$ & $1.131 \mathrm{ba}$ & $1.705 \mathrm{a}$ & $1.471 \mathrm{a}$ \\
1,5 & $1.624 \mathrm{ba}$ & - & - & $1.506 \mathrm{a}$ \\
2,4 & $1.494 \mathrm{ba}$ & $1.052 \mathrm{cba}$ & $1.549 \mathrm{ba}$ & - \\
Controle $\left(70 \mathrm{~kg} \mathrm{ha}^{-1} \mathrm{de} \mathrm{N}\right)$ & $1.515 \mathrm{ba}$ & $1.283 \mathrm{a}$ & $1.595 \mathrm{ba}$ & $1.451 \mathrm{a}$ \\
\hline $\mathrm{CV}(\%)$ & 9,51 & 17,16 & 17,85 & 13,61 \\
\hline
\end{tabular}

${ }^{(1)}$ Médias seguidas de letras iguais, nas colunas, não diferem pelo teste $\mathrm{t}$ (LSD), a 5\% de probabilidade. ${ }^{(2)}$ Área de primeiro cultivo. ${ }^{(3)}$ Área com cultivo anterior de soja (Glycine max). ${ }^{(4)}$ Densidade - unidades formadoras de colônia (UFC) por semente - não testada no experimento na região. 
com $\mathrm{N}$ proporcionou rendimento de grãos acima do da inoculação com $0,3 \times 10^{6}$ UFC por semente, mas estatisticamente igual ao das demais densidades (Tabela 2). Isso indica que outros fatores, especialmente edafoclimáticos, podem ter limitado a produtividade das plantas.

$\mathrm{Na}$ área já cultivada na região Norte, todos os tratamentos apresentaram produtividade acima de $1.000 \mathrm{~kg} \mathrm{ha}^{-1}$, enquanto, na área de primeiro cultivo, o tratamento não inoculado e o tratamento inoculado com $0,3 \times 10^{6}$ UFC por semente apresentaram produtividade abaixo de $1.000 \mathrm{~kg} \mathrm{ha}^{-1}$. Isso indica a necessidade da inoculação em áreas de primeiro cultivo; mesmo em áreas já cultivadas e com população de rizóbios estabelecida, verificou-se que a inoculação com $1,2 \times 10^{6}$ UFC por semente proporcionou um aumento de produtividade de $455 \mathrm{~kg} \mathrm{ha}^{-1}$ em relação ao tratamento não inoculado. Silva et al. (2011) também observaram que, ao dobrar a dose inoculada, houve aumento no rendimento de grãos de soja acima de $250 \mathrm{~kg} \mathrm{ha}^{-1}$.

$\mathrm{O}$ aumento da densidade de células rizobianas nas sementes possibilitou aumento linear na massa de nódulos, nos experimentos instalados na região CentroOeste e na área cultivada da região Norte (Figura 1), o que caracteriza uma estratégia para maximizar os benefícios da inoculação (Krasova-Wade et al., 2006; Silva et al., 2012). No entanto, nos outros dois experimentos, no Sudeste e na área recém cultivada na região Norte, apesar do aumento da nodulação em função da inoculação, em praticamente todas as doses, não se detectou influência do aumento da densidade de rizóbios na semente sobre a nodulação. Isso provavelmente pode ser explicado pela presença de uma população de rizóbios estabelecida no solo, evidenciada pela abundante nodulação do tratamento sem inoculação (Thies et al., 1991; Soares et al., 2014).

Em termos de rendimento de grãos, os dados obtidos mostraram que a inoculação foi importante para elevar os ganhos, em comparação aos tratamentos sem inoculante e nitrogenado (Tabela 2). O aumento da densidade de UFC de rizóbios por semente, por sua vez, proporcionou elevação nos ganhos de produtividade, e a dose de 1,2 milhão de UFC por semente esteve entre as melhores para todos os experimentos (Figura 3 e Tabela 2). Além disso, observou-se que, no experimento de primeiro cultivo na região Norte, não houve relação entre a densidade de rizóbios na semente e o rendimento de grãos, e que, no experimento na área cultivada nessa mesma região e no experimento no Sudeste, houve indicação de redução nas doses superiores a 1,2 milhão UFC de rizóbios por semente. É provável que tanto a população de rizóbios do solo quanto os fatores edáficos estejam envolvidos nessas respostas.

\section{Conclusões}

1. A nodulação na cultura do feijão-caupi (Vigna unguiculata) responde positivamente ao aumento da densidade de células de rizóbios aplicadas nas sementes.

2. Há aumento linear da nodulação das plantas com o aumento da densidade da inoculação, porém não necessariamente com resposta na biomassa da parte aérea.

3. A densidade de células de rizóbios nas sementes, capaz de proporcionar o maior rendimento de grãos do feijão-caupi, deve ser de, no mínimo, $1,2 \times 10^{6}$ unidades formadoras de colônias por sementes.

\section{Agradecimentos}

À Coordenação de Aperfeiçoamento de Pessoal de Nível Superior (Capes), pela concessão de bolsa de estudos.

\section{Referências}

BELANE, A.K.; DAKORA, F.D. Symbiotic $\mathrm{N}_{2}$ fixation in 30 field-grown cowpea (Vigna unguiculata L. Walp.) genotypes in the Upper West Region of Ghana measured using ${ }^{15} \mathrm{~N}$ natural abundance. Biology and Fertility of Soils, v.46, p.191-198, 2010. DOI: 10.1007/s00374-009-0415-6.

BORGES, P.R.S.; SABOYA, R. de C.C.; SABOYA, L.M.F.; SANTOS, E.R. dos; SOUZA, S.E.A. de. Distribuição de massa seca e rendimento de feijão-caupi inoculadas com rizóbio em Gurupi, TO. Revista Caatinga, v.25, p.37-44, 2012.

BRASIL. Ministério da Agricultura, Pecuária e Abastecimento. Instrução normativa $n^{\circ} 13$, de 24 de março de 2011. Aprova as normas sobre especificações, garantias, registro, embalagem e rotulagem dos inoculantes destinados à agricultura, bem como as relações dos micro-organismos autorizados e recomendados para produção de inoculantes no Brasil, na forma dos Anexos I, II e III, desta Instrução. Diário Oficial [da] República Federativa do Brasil, 25 mar. 2011. Seção 1, p.3-7.

CAMPO, R.J.; ARAUJO, R.S.; MOSTASSO, F.L.; HUNGRIA, M. In-furrow inoculation of soybean as alternative to fungicide and micronutrient seed treatment. Revista Brasileira de Ciência do Solo, v.34, p.1103-1112, 2010. DOI: 10.1590/ S0100-06832010000400010. 
CHAGAS JUNIOR, A.F.; RAHMEIER, W.; FIDELIS, R.R.; SANTOS, G.R. dos; CHAGAS, L.F.B. Eficiência agronômica de estirpes de rizóbio inoculadas em feijão-caupi no Cerrado, Gurupi-TO. Revista Ciência Agronômica, v.41, p.709-714, 2010. DOI: $10.1590 / \mathrm{S} 1806-66902010000400027$.

CLAESSEN, M.E.C. (Org.). Manual de métodos de análise de solo. 2.ed. rev. atual. Rio de Janeiro: Embrapa-CNPS, 1997. 212p. (Embrapa-CNPS. Documentos, 1).

COSTA, E.M.; NÓBREGA, R.S.A.; MARTINS, L. de V.; AMARAL, F.H.C.; MOREIRA, F.M. de S. Nodulação e produtividade de Vigna unguiculata (L.) Walp. por cepas de rizóbio em Bom Jesus, PI. Revista Ciência Agronômica, v.42, p.1-7, 2011. DOI: $10.1590 / \mathrm{S} 1806-66902011000100001$.

FERNANDES JÚNIOR, P.I.; ROHR, T.G.; OLIVERA, P.J. de; XAVIER, G.R.; RUMJANEK, N.G. Polymers as carriers for rhizobial inoculant formulations. Pesquisa Agropecuária Brasileira, v.44, p.1184-1190, 2009. DOI: 10.1590/ S0100-204X2009000900017.

FERNANDES JÚNIOR, P.I.; SILVA JÚNIOR, E.B. da; SILVA JÚNIOR, S. da; SANTOS, C.E.R. da S. e; OLIVEIRA, P.J. de; RUMJANEK, N.G.; MARTINS, L.M.V.; XAVIER, G.R. Performance of polymer compositions as carrier to cowpea rhizobial inoculant formulations: survival of rhizobia in pre-inoculated seeds and field efficiency. African Journal of Biotechnology, v.11, p.2945-2951, 2012. DOI: 10.5897/AJB11.1885.

FERREIRA, D.F. SISVAR: um programa para análises e ensino de estatística. Revista Symposium, v.6, p.36-41, 2008.

FERREIRA, L. de V.M.; NÓBREGA, R.S.A.; NÓBREGA, J.C.A.; AGUIAR, F.L. de; MOREIRA, F.M. de S.; PACHECO, L.P. Biological nitrogen fixation in production of Vigna unguiculata (L.) Walp, family farming in Piauí, Brazil. Journal of Agricultural Science, v.5, p.153-160, 2013. DOI: 10.5539/jas.v5n4p153.

FILGUEIRAS, G.C.; SANTOS, M.A.S. dos; HOMMA, A.K.O.; REBELLO, F.K.; CRAVO, M.S. Aspectos socioeconômicos. In: ZILLI, J.E.; VILARINHO, A.A.; ALVES, J.M.A. (Ed.). A cultura do feijão-caupi na Amazônia brasileira. Boa Vista: Embrapa Roraima, 2009. p.23-58.

FREIRE FILHO, F.R. (Ed.). Feijão-caupi no Brasil: produção, melhoramento genético, avanços e desafios. Teresina: Embrapa Meio-Norte, 2011. 84p.

KRASOVA-WADE, T.; DIOUF, O.; NDOYE, I.; SALL, C.E.; BRACONNIER, S.; NEYRA, M. Water-condition effects on rhizobia competition for cowpea nodule occupancy. African Journal of Biotechnology, v.5, p.1457-1463, 2006.

LACERDA, A.M.; MOREIRA, F.M. de S.; ANDRADE, M.J.B. de; SOARES, A.L. de L. Efeito de estirpes de rizóbio sobre a nodulação e produtividade do feijão caupi. Revista Ceres, v.51, p.67-82, 2004.

MARINHO, R. de C.N.; NÓBREGA, R.S.A.; ZILLI, J.É.; XAVIER, G.R.; SANTOS, C.A.F.; AIDAR, S. de T.; MARTINS, L.M.V.; FERNANDES JÚNIOR, P.I. Field performance of new cowpea cultivars inoculated with efficient nitrogen-fixing rhizobial strains in the Brazilian Semiarid. Pesquisa Agropecuária Brasileira, v.49, p.395-402, 2014. DOI: 10.1590/S0100-204X2014000500009.
MARTINS, L.M.V.; XAVIER, G.R.; RANGEL, F.W.; RIBEIRO, J.R.A.; NEVES, M.C.P.; MORGADO, L.B.; RUMJANEK, N.G. Contribution of biological nitrogen fixation to cowpea: a strategy for improving grain yield in the semi-arid region of Brazil. Biology and Fertility of Soils, v.38, p.333-339, 2003. DOI: 10.1007/ s00374-003-0668-4.

MENDES, I.C.; HUNGRIA, M.; VARGAS, M.A.T. Establishment of Bradyrhizobium japonicum and B. elkanii strains in a Brazilian Cerrado oxisol. Biology and Fertility of Soils, v.40, p.28-35, 2004. DOI: $10.1007 / \mathrm{s} 00374-004-0739-1$.

PULE-MEULENBERG, F.; BELANE, A.K.; KRASOVA-WADE, T.; DAKORA, F.D. Symbiotic functioning and bradyrhizobial biodiversity of cowpea (Vigna unguiculata L. Walp.) in Africa. BMC Microbiology, v.10, p.1471-2180, 2010. DOI: 10.1186/1471-2180-10-89.

SANTOS, H.G. dos; JACOMINE, P.K.T.; ANJOS, L.H.C. dos; OLIVEIRA, V.A. de; OLIVEIRA, J.B. de; COELHO, M.R.; LUMBRERAS, J.F.; CUNHA, T.J.F. (Ed.). Sistema brasileiro de classificação de solos. 2.ed. Rio de Janeiro: Embrapa Solos, 2006. $306 \mathrm{p}$.

SILVAJÚNIOR, E.B. da; FERNANDES JÚNIOR, P.I.; OLIVEIRA, P.J. de; RUMJANEK, N.G.; BODDEY, R.M.; XAVIER, G.R. Eficiência agronômica de nova formulação de inoculante rizobiano para feijão-caupi. Pesquisa Agropecuária Brasileira, v.47, p.138-141, 2012. DOI: 10.1590/S0100-204X2012000100019.

SILVA, A.F. da; CARVALHO, M.A.C. de; SCHONINGER, E.L.; MONTEIRO, S.; CAIONE, G.; SANTOS, P.A. Doses de inoculante e nitrogênio na semeadura da soja em área de primeiro cultivo. Bioscience Journal, v.27, p.404-412, 2011.

SILVA, M. de F. da; SANTOS, C.E. de R. e S.; SOUSA, C.A. de; ARAÚJO, R.de S.L.; STAMFORD, N.P.; FIGUEIREDO, M.do V.B. Nodulação e eficiência da fixação do $\mathrm{N}_{2}$ em feijão-caupi por efeito da taxa do inóculo. Revista Brasileira de Ciência do Solo, v.36, p.1418-1425, 2012. DOI: 10.1590/S0100-06832012000500005.

SOARES, A.L. de L.; PEREIRA, J.P.A.R.; FERREIRA, P.A.A.; VALE, H.M.M. do.; LIMA, A.S.; ANDRADE, M.J.B. de; MOREIRA, F.M. de S. Eficiência agronômica de rizóbios selecionados e diversidade de populações nativas nodulíferas em Perdões (MG). I - Caupi. Revista Brasileira de Ciência do Solo, v.30, p.795-802, 2006. DOI: 10.1590/S0100-06832006000500006.

SOARES, B.L.; FERREIRA, P.A.A.; OLIVEIRA-LONGATTI, S.M. de; MARRA, L.M.; RUFINI, M.; ANDRADE, M.J.B. de; MOREIRA, F.M. de S. Cowpea symbiotic efficiency, $\mathrm{pH}$ and aluminum tolerance in nitrogen-fixing bacteria. Scientia Agricola, v.71, p.171-180, 2014. DOI: 10.1590/S0103-90162014000300001.

THIES, J.E.; SINGLETON, P.W.; BOHLOOL, B.B. Influence of the size of indigenous rhizobial populations on establishment and symbiotic performance of introduced rhizobia on field-grown legumes. Applied and Environmental Microbiology, v.57, p.19-28, 1991.

ZILLI, J.É.; MARSON, L.C.; MARSON, B.F.; RUMJANEK, N.G.; XAVIER, G.R. Contribuição de estirpes de rizóbio para o desenvolvimento e produtividade de grãos de feijão-caupi em Roraima. Acta Amazonica, v.39, p.749-758, 2009. DOI: 10.1590/ S0044-59672009000400003. 
ZILLI, J.É.; PEREIRA, G.M.D.; FRANÇA JÚNIOR, I.; SILVA, K. da; HUNGRIA, M.; ROUWS, J.R.C. Dinâmica de rizóbios em solo do cerrado de Roraima durante o período de estiagem. Acta Amazonica, v.43, p.153-160, 2013. DOI: 10.1590/ S0044-59672013000200004.
ZILLI, J.É.; SILVA NETO, M.L. da; FRANÇA JÚNIOR, I.; PERIN, L.; MELO, A.R. de. Resposta do feijão-caupi à inoculação com estirpes de Bradyrhizobium recomendadas para a soja. Revista Brasileira de Ciência do Solo, v.35, p.739-742, 2011. DOI: $10.1590 /$ S0100-06832011000300009.

Recebido em 27 de fevereiro de 2014 e aprovado em 22 de setembro de 2014 